\title{
LA EMERGENCIA DE SEVILLA ${ }^{1}$
}

\section{THE EMERGENCE OF SEVILLA}

\author{
por
}

\author{
MANUEL PELLICER CATALÁN
}

RESUMEN Los alrededores de Sevilla estuvieron intensamente ocupados durante la Prehistoria Reciente. En el Hierro Antiguo, los habitantes de la zona bajan a la antigua desembocadura del Guadalquivir y fundan la ciudad; movimientos causados por el comercio fenicio.

ABSTRACT The ancient mouth Guadalquivir region were inhabited intensely during the Late Prehistory. People of the area moved to the valley and founded the city of Seville in the First Iron Age. The Phoenician trade was the cause of that emergence.

\section{I.- ANTECEDENTES}

En los estudios arqueológicos de las culturas o de los yacimientos siempre se ha prestado especial atención a su origen. Si los datos arqueológicos han sido insuficientes o mal interpretados, lógicamente se llega a conclusiones erróneas, cuando no absurdas. Antes de los años sesenta el problema del origen y formación de las culturas se resolvía, siguiendo sustancialmente la escuela histórico-cultural, mediante el fenómeno de la difusión, entendiendo como tal la invasión desde núcleos culturales más evolucionados.

Las teorías invasionistas sobre nuestra prehistoria reciente y protohistoria se desvanecieron drásticamente ante las evidencias cronológicas del C-14 (Renfrew 1986) y con la aparición de la arqueología procesual de los años setenta, independientemente de que negaba gratuitamente la difusión, suplantada por la evolución y por el autoctonismo (Binford 1962), introduciéndose otros modelos, factores o variables, propios de la antropología social anglosajona, explicativos del proceso evolutivo del cambio cultural.

1. Estas notas son consecuencia de una conferencia que pronuncié en la sede de la Real Academia de Bellas Artes de Santa Isabel de Hungría de Sevilla el día 11 de marzo de 1.997 y que, por sugerencia del Prof. J.L. Escacena, recompuesto el texto, se publica en la revista $S P A L$ del Departamento de Prehistoria y Arqueología de la Universidad de Sevilla. 
No cabe duda de que la arqueología procesual ha añadido a la metodología de la investigación arqueológica nuevas pautas y derroteros sumamente valiosos, pero con un negativo gravamen, su exacervado dogmatismo, exclusivista y pretencioso de estar en posesión de la verdad. El simplismo del viejo difusionismo cambió de signo hacia el punto diametralmente opuesto de un radical autoctonismo y evolucionismo, que adolecía en los mismos defectos unilaterales que los de la anterior tendencia (Pellicer 1995).

Ante los evidentes errores con que ambas tendencias, radicalizadas, han deteriorado la investigación, parece plausible aceptar prudentemente aquellos modelos explicativos que sean más verosímiles, cuando no evidentes, sean del signo que sea. En este caso, al indagar sobre los orígenes o emergencia de la ciudad de Sevilla, concebida como un microsistema medioambiental y cultural, cabría contemplar, en conjunto, tanto los factores evolucionistas-como los difusionistas, que contribuyeron al desarrollo de esa sociedad del Bronce final. Estos factores pudieron ser el cambio del ecosistema con la aparición del período climático subatlántico, las nuevas tecnologías metalúrgicas atlánticas y ultrapirenaicas, la fuerte eclosión demográfica, la nueva complejidad social, la interacción económica con respecto a otra sociedad más culta y avanzada como la fenicia y la integración político-económica de la nueva ciudad, dependiente de un centro nuclear de poder, como sería el poblado de El Carambolo.

\section{II.- EL ECOSISTEMA}

En la investigación sobre los orígenes de Sevilla en modo alguno podemos prescindir de un factor fundamental como el ecosistema de su entorno, bien entendido que la ciudad surge no exclusivamente en función del medio ambiente, según el principio de la teoría de los sistemas (Clarke 1984), sino también en los factores enumerados, entre los que habría que destacar enfáticamente la puesta en escena de la presencia fenicia, que no deja de ser un fenómeno de difusión cultural.

El entorno sevillano, sedimentario (Vanney 1970; Menanteau 1982; Escacena 1983; Díaz del Olmo 1989; Borja 1995), está constituido, en su primera fase, por un sustrato neógeno, formado en el mioceno-plioceno durante casi 30 millones de años y compuestos por margas azules y calizas fosilíferas o albero. Este sustrato, en una segunda fase, fue excavado en casi un centenar de metros por el Guadalquivir, formándose en toda su amplitud el cauce bajo y apareciendo un delta de sedimentos fluviales desde el pleistoceno, hace unos 2.000.000 de años, y durante el holoceno, vertiéndose la corriente del río en una gran ensenada o marismas a la altura de Puebla del Río. Este delta donde se asienta Sevilla, sufre los efectos de la erosión en ciertos puntos y de acumulación de gravas en otros, surgiendo una serie de islotes, sometidos a frecuentes inundaciones.

En una tercera fase, coincidiendo con el cambio climático del subboreal al subatlántico, hacia los inicios del I milenio a.C., el río deja de ser torrencial, según se constata por la ausencia de gravas, estabilizándose, para convertirse en una serie de corrientes lentas por varios brazos, como efecto de la elevación de su nivel de base y apareciendo los numerosos canales del delta que depositan sedimentos de arenas y limos. En uno de esos islotes rodeados de canales de la llanura aluvial, tendrá lugar el primer asentamiento de la ciudad. Esta llanura aluvial con una anchura de unos $6 \mathrm{~km}$ entre el Aljarafe al W., elevado un centenar de metros, y Los Alcores al E., que asciende en suave declive, se extiende hacia el S., hasta la marisma en Puebla del Río.

\section{III.- EL POBLAMIENTO PREHISTÓRICO DEL ENTORNO}

Independientemente de la presencia de restos del Paleolítico inferior y medio hallados en las graveras de las terrazas medias y bajas del Guadalquivir (Vallespi 1988), el primer poblamiento estable del entorno de Sevilla se documenta intensamente en los bordes orientales del Aljarafe. Y esporádicamente en la llanura 
aluvial. Otro foco importante de poblamiento se localiza hacia el E., en el borde oriental de Los Alcores, entre Carmona y Alcalá de Guadaira, a unos $20 \mathrm{~km}$ de Sevilla, donde florece un brillante Calcolítico dentro del III milenio e inicios del II a.C.

Estas poblaciones calcolíticas o de la Edad del Cobre prefieren emplazamientos a media altura, condicionados por un ecosistema capaz de proporcionarles una segura protección contra los peligros de la inundación del río y una salubridad que no hubieran hallado en el fondo del valle. Por otra parte, la altura los dota de una especial estrategia y visibilidad, previsora de posibles problemas ofensivos en un momento en que la acumulación de excedentes alimenticios agropecuarios podría ser objeto de codicia por parte de otros grupos rivales.

Aunque las excavaciones arqueológicas no han documentado evidentes defensas artificiales en los poblados, resulta plausible creer que éstas existieran, no de piedra, dada su ausencia en la geología del terreno, sino de fosos y empalizadas, difíciles de detectar en unas excavaciones de urgencia.

Dado el tipo de economía del Calcolítico, basada en la ganadería de ovicápridos y bóvidos, en la caza del ciervo y jabalí y en una agricultura cerealista de secano, los emplazamientos en el borde del Aljarafe se acomodan perfectamente a la misma con unas áreas idóneas para la captación de sus recursos alimenticios, extendidas hacia el interior del Aljarafe y hacia la parte septentrional, por los campos occidentales del actual Santiponce (Escacena 1983), sin que dejaran de explotar igualmente la llanura aluvial del Guadalquivir en estaciones propicias.

Los excedentes alimenticios dẹ cereales podían conservarse en la altura con más seguridad que en el húmedo valle de inundación, según se confirma en los campos de silos con centenares de estructuras abiertas en la marga en Valencina de la Concepción, en la estacada de Alfaro de Puebla del Río (Carriazo 1974) o en el Campo de las Canteras de Carmona (Cruz-Auñón y Jiménez 1986).

Prescindiendo del borde oriental de Los Alcores, desde Carmona a Gandul, donde se descubrió un buen lote de poblados y necrópolis calcolíticos (Bonsor 1899; Amores 1982), la población se condensa primordialmente en el borde del Aljarafe, mirando el núcleo principal Valencina.

En Valencina (Ruiz Mata 1975 y 1983) se emplaza un asentamiento calcolítico, nuclear, de vastas dimensiones, uno de los mayores que ha proporcionado el territorio, más extenso que sus coetáneos peninsulares, como los Millares (Santa Fe de Modujar, Almería) (Almagro Basch y Arribas 1963), Vilanova de São Pedro (Lisboa, Portugal) (Paço y Sangmeister 1953) o la Mesa de Gandul (Alcalá de Guadaira, Sevilla) (Pellicer y Hurtado .1987).

Según los datos suministrados por las excavaciones, efectuadas en Valencina desde los años sesenta por J.M ${ }^{\mathbf{a}}$ Blázquez, D. Ruiz Mata y otros, y por los trabajos de urgencia actualmente en curso, dirigidos por O. Arteaga y R. Cruz-Auñón, el núcleo poblacional consta de cabañas de planta circular construidas con barro y ramaje, excavadas en las margas miocenas-pliocenas, de un diámetro de 4-5 $\mathrm{m}$, alternando con silos de 2-3 m de profundidad, troncocónicos, y por unas problemáticas zanjas de perfil en $\mathrm{V}$, probables elementos de separación o con función de drenaje de los silos. El hábitat propiamente dicho se extiende bajo el actual municipio en una extensión de unas $20 \mathrm{Ha}$, lo que hace suponer una demografía de más de 2.000 habitantes. Según información de O. Arteaga, este núcleo de habitación continúa hacia el SW con un gran recinto trapezoidal de unas $70 \mathrm{Ha}$, delimitado por zanjas, análogas a las anteş aludidas, y repleto de silos, cuya función sería redil para ganado y almacén de cereales. En el límite occidental y meridional de este recinto se sitúa la necrópolis principal y principesca de tipo megalítico, a la que pertenecen los famosos tholoi de La Pastora, Ontiveros y Matarrubilla (Collantes de Terán 1969), junto con medio centenar de pequeños tholoi, correspondientes a la clase inferior, actualmente en proceso de excavación. En el borde septentrional, hacia Santiponce, la necrópolis prosigue con otros enterramientos, también en tholoi, como el de la Cabeza (Fernández y Oliva 1986; Fernández y Ruiz 1978). 
Posiblemente en esta gran concentración de Valencina estarían integrados política y económicamente otros poblados menores, como los de La Algaba y El Carambolo, con vaso campaniforme, y el de Santa Eufemia (Buero y otros 1978; Escacena 1983). Más al S., con cierta independencia, se emplazan los poblados calcolíticos del Cerro de San Juan (Coria del Río) (Cañal 1894; Hernández Díaz y otros 1938; Escacena 1983), actualmente en proceso de excavación por J.L. Escacena.

En el borde de la marisma, en el término de Puebla del Río, fue estudiado un interesante yacimiento, no de hábitat, sino de pequeña factoría para la producción y distribución de sal, La Marismilla, con la cronología más arcaica del entorno, puesto que a través de sus cerámicas podría fecharse en la transición del Neolítico al Calcolítico, a finales del IV milenio a.C. (Escacena y otros1996).

En la llanura aluvial, por hallazgos casuales, se conocen algunos puntos con presencia calcolítica en pequeños altozanos dentro del actual perímetro de Sevilla y en el extrarradio. En la Puerta de Jerez, según noticias del pasado siglo, se descubrió un dolmen, dato que nos parece dudoso, primeramente porque no corresponde al emplazamiento normal de este tipo de monumento funerario, ya que suele agruparse en emplazamientos más elevados. En segundo lugar, por estar la Puerta de Jerez en una cota excesivamente baja, de unos $9 \mathrm{~m}$ s.n.m., expuesta a fuertes inundaciones. Es posible que unos restos monumentales romanos se confundiesen con un monumento megalítico.

En la parte nororiental de Sevilla, en la Fuente del Arzobispo, junto al Tamarguillo, tenemos noticias de la aparición de industria lítica y cerámica a mano amorfa (Candau 1894; Collantes de Terán 1977; Escacena 1983), atribuidas igualmente al calcolítico, lo que induciría a pensar en un asentamiento temporal, estacionalmente utilizado para caza, pastoreo o trabajos agrícolas. Lo mismo podría conjeturarse sobre el yacimiento con fondos de cabaña y vaso campaniforme localizado en la Universidad Laboral, al N. de la carretera de Utrera (Fernández y Alonso 1985). Finalmente, junto a La Algaba, en el paraje denominado Las Arenas, se sucedieron hallazgos de vaso campaniforme en las prospecciones de D. Ruiz Mata.

Entrado el II milenio a.C., hacia el 1700 a.C., tiene lugar un fenómeno, todavía no explicado correctamente, de un despoblamiento general en el valle medio y bajo del Guadalquivir. Los abundantes yacimientos calcolíticos pierden su identidad o se despueblan, sumiéndose el territorio en un hiatus o vacío realmente problemático, para cuya recuperación tenemos que esperar hasta el s. X o IX a.C. Este despoblamiento contrasta grandemente con el comportamiento de la periferia del Guadalquivir, especialmente con la Sierra Morena Occidental, donde se localizan poblados y necrópolis con fosas o cistas de la Edad del Bronce, como Setefilla (Lora del Río) (Aubet 1981), la Sierra de Huelva (Amo 1975), El Trastejón (Zufre, Huelva) (Hurtado y García 1994), Sanlúcar la Mayor (Fernández y Ruiz 1976), etc. Este contraste se acentúa todavía más con el Algarve y Alentejo portugués (Gamito 1988) y muy especialmente con la riqueza del bronce argárico de Andalucía Oriental (H. y L. Siret 1890; Blance 1971).

La explicación más plausible de este supuesto despoblamiento podría ser el cambio de emplazamiento de los hábitats, que buscaban zonas más escarpadas y cotas más elevadas, inexistentes en el valle medio y bajo del Guadalquivir y en las campiñas, motivado por la actitud conflictiva de unas sociedades, ya clasistas, que trabajaban, almacenaban y comerciaban con la metalurgia del cobre y de la plata de la franja piritífera del SW y con el estaño del NW y que preludiaban la aparición del estado tartésico. Quizás cuando las prospecciones arqueológicas se efectúen con metodología más depurada en Sierra Morena y en puntos estratégicos de la Campiña y de la Subbética, cambie el panorama de nuestros conocimientos sobre la plena Edad del Bronce en nuestra región.

Hacia una fecha imprecisa del tercer cuarto del II milenio a.C. la arqueología detecta, no sólo en Andalucía sino en el resto peninsular, una serie de cambios culturales que los investigadores han catalogado de Bronce tardío o Bronce final I, etapa todavía bastante oscura, caracterizada por la aparición de una nueva metalurgia de tipo atlántico y centroeuropeo (Ruiz Gálvez 1984; Coffyn 1985), por la cerámica de boquique, al parecer de origen meseteño, por el cambio de emplazamiento de los poblados en cotas más bajas y por la sorprendente ausencia de necrópolis. 


\section{IV.- EL POBLAMIENTO PROTOHISTÓRICO DEL ENTORNO}

Entrado el I milenio a.C., mientras en Andalucía Oriental se advierte una rarificación de los yacimientos con el consiguiente descenso demográfico, en el Valle del Guadalquivir sucede el fenómeno contrario, asistiéndose a una fuerte eclosión demográfica con la multiplicación de los yacimientos del Bronce final, propiamente tartésicos.

En el entorno de Sevilla la población del Aljarafe se expande, ocupando la baja llanura aluvial y surgiendo nuevos poblados paralelos, en la segunda mitad del s. VIII a.C.: el Cerro de la Cabeza (Santiponce), el Cerro Macareno (San José de la Rinconada), La Algaba y Sevilla, persistiendo en la altura los importantes núcleos del Carambolo (Camas), Valencina, el Cerro de San Juan (Coria del Río) y Santa Eufemia.

El Cerro de la Cabeza (Domínguez y otros 1988), como sucesor del poblado de Valencina, con un nuevo emplazamiento en la orilla derecha del brazo del Guadalquivir denominado la Madre Vieja, con una estratigrafía de $4 \mathrm{~m}$ de potencia, entregó cuatro poblados superpuestos dentro de una cronología desde la segunda mitad del s. VIII a.C. hasta fines del s. V a.C., momento en que la población se traslada unos $800 \mathrm{~m}$ al S., al actual casco urbano de Santiponce (Pellicer y otros 1982), ocupando el Cerro de San Antonio y los Palacios. El desplazamiento de la población desde el Cerro de la Cabeza a Santiponce se debió sin duda al cambio de rumbo de la Madre Vieja, que lamía los muros de este último emplazamiento, convertido en el año 206 en la Itálica de Escipión, donde asentó a los legionarios heridos, vencedores de la batalla de Ilipa contra los cartagineses.

En un meandro del Guadalquivir, a $9 \mathrm{~km}$ al N. de Sevilla, y a mediados del s. VIII a.C. se puebla el Cerro Macareno, cuya excavación (Pellicer y otros 1983) entregó 8 poblados superpuestos en una estratigrafía de $8 \mathrm{~m}$ de potencia, cuya cronología va desde el 750 a.C. hasta el 100 a.C. Destruidas las tres cuartas partes del yacimiento para la explotación de áridos, su extensión primitiva se supone de unas 4 Ha con una demografía de unos 800 habitantes. La función del Cerro Macareno debió ser de tipo agropecuario y comercio fluvial, según el nutrido elenco de ánforas fenicias, griegas, púnicas y romanas republicanas, generalmente fabricadas in situ para explotación de alimentos. El ocaso del Cerro Macareno parece que igualmente obedeció a la desaparición del meandro del Guadalquivir que rodeaba el yacimiento, perdiendo su función comercial.

El Carambolo es uno de los yacimientos más prestigiosos del orientalizante sevillano, situado a $60 \mathrm{~m}$ sobre la llanura aluvial y a $3 \mathrm{~km}$. de Sevilla. Descubierto su famoso tesoro tartésico en 1958, J. de M. Carriazo efectuó las excavaciones, primeramente, en el lugar del hallazgo y, a continuación, en una zona contigua más baja (1973). La actuación en el lugar del hallazgo, denominado Carambolo alto, dio por resultado la localización de un fondo de cabaña de planta circular, de barro y materiales perecederos, del Bronce final, dentro de una estratigrafía, lamentablemente confusa, que arrancando desde principios del II milenio a. C., termina hacia el 500 a. C., habiéndose identificado por J. Maluquer (1959) la fecha de ocultación del tesoro a fines del s. VI a. C..

Parece plausible creer que el tesoro se escondió en el momento de destrucción o abandono del Carambolo, coincidente con el primer incendio de Sevilla, hacia el 500 o primer cuarto del s. V a. C., según explicamos más adelante.

El poblado bajo del Carambolo fue excavado en una superficie de unos $250 \mathrm{~m}^{2}$, entregando una estratigrafía de cuatro poblados superpuestos de singular relevancia arquitectónica y de rico y variado registro arqueológico, correspondiente a las fases II y III de Carriazo, con una cronología hasta mediados del s. V a. C., momento del abandono del yacimiento, cuya población fue absorbida por Sevilla.

Recientemente O. Arteaga y R. Cruz-Auñón han descubierto y excavado su monumental necrópolis, fechada en el s. VII a. C., con enormes túmulos circulares de un diámetro de medio centenar de metros y con cámaras de inhumación, desgraciadamente arrasadas en su totalidad. 
Si el Carambolo se hubiera excavado con las debidas garantías científicas y con una metodología más depurada, podría disponerse ahora de una preciosa documentación, necesaria para la explicación de la problemática del mundo tartesio del Bajo Guadalquivir y de los orígenes de Sevilla. Es difícil comprender cómo todavía, después de 35 años, no se ha gestionado, por parte de la Consejería de Cultura de la Junta de Andalucía y del Ayuntamiento de Sevilla, la expropiación y la excavación sistemática del Carambolo bajo la dirección de un competente arqueólogo, de ese yacimiento espectacular donde se hunden las raíces de Sevilla. Quizás dentro de unos años ya sea tarde.

\section{V.- EL POBLAMIENTO DE SEVILLA}

Sobre los orígenes de Sevilla ya San Isidro en sus Etimologías buscaba las raíces del nombre de la ciudad absurdamente en His palis, como si de una ciudad palafítica se tratase. Desde el s. XVI hasta mediados del XX las escasas noticias de las fuentes clásicas se mezclaban con las leyendas ante la ausencia de fuentes arqueológicas (Caro 1932, Bermúdez 1832). Tenemos que llegar a los años cuarenta de nuestro siglo para obtener los primeros datos científicos de tipo arqueológico en que sustentar el problema, habiendo sido pionero F. Collantes de Terán (1977), quien desveló por vez primera el subsuelo sevillano y en cuyos trabajos basaron sus monografías sevillanas J. M. Carriazo (1974) y A. Blanco (1979). En los años ochenta prosiguió la labor investigadora de sondeos estratigráficos en el solar hispalense por arqueólogos con una metodología más depurada, aportando la valiosa documentación de que ahora disponemos, entre los que cabe destacar J. Campos (1986 y 1988) y M. Vera (1986), sin que podamos omitir las acertadas interpretaciones de J. L. Escacena (1983) y de M. Belén y J. L. Escacena (1995).

Retomando el hilo de nuestra disertación, Sevilla emerge, paralela a los cerros de la Cabeza y del Macareno y en un análogo ecosistema, en la segunda mitad del s. VIII a.C., como un suburbio portuario y comercial del rico núcleo tartésico del Carambolo, representando en relación con éste el mismo fenómeno que el establecimiento portuario etrusco de Pyrgi con respecto a Caere.

La Sevilla primitiva se emplaza al NW de un islote emergido entre los meandros y brazos del Guadalquivir, en una cota entre 17 y 15 m s.n.m., en el centro de la calle San Isidoro (Campos y otros 1988) y con una superficie difícil de calcular por falta de sondeos suficientes, pero presumiblemente ovalada, de unos $300 \mathrm{~m}$ $\mathrm{N}-\mathrm{S}$ por $100 \mathrm{E}-\mathrm{W}$, lo que correspondería a una población de 600 habitantes.

Las causas del desplazamiento de la población desde el Aljarafe hasta la llanura aluvial del Guadalquivir serían múltiples y variadas. En primer lugar, el cambio climático del subboreal al subatlántico, ocurrido en los inicios del I milenio a. C., producía una relativa estabilización del ritmo del río, de manera que el valle adquirió mejores condiciones de habitabilidad. La pacificación, constatada, en general, por los emplazamientos más bajos de los poblados, como si hubiese desaparecido el peligro bélico, no dejaría de contribuir al nacimiento de Sevilla. La adecuación del valle para ser agropecuariamente explotado fue una causa económicamente decisiva. La fértil vega del Guadalquivir dio paso a una floreciente agricultura de regadío, ayudada por la adaptación del arado, que debió aparecer en estos momentos. Por otra parte, la ganadería bovina y ovicaprina encontraría cerca de los poblados inmensas extensiones de pastos. Una nueva tecnología relativa al transporte fluvial y terrestre de productos agropecuarios y minerales con la aparición del carro, según las representaciones de las estelas grabadas del SW (Almagro Basch 1966), y nuevos tipos de embarcaciones fomentarían el fluido comercio. Ante la perspectiva la sociedad tartésica hispalense estaba ya en condiciones adecuadas y en un nivel cultural propio para un profundo cambio económico y social, al que contribuiría decisivamente el gran catalizador de la presencia fenicia en el bajo Guadalquivir, que demandaba los productos de los que sus metrópolis orientales carecían. 
Existen serias dudas sobre si los establecimientos antes mencionados del Cerro de la Cabeza, El Macareno, La Algaba y Sevilla, se inician inmediatamente antes del contacto con los colonizadores fenicios o si el contacto fue la causa inmediata de la emergencia de estos establecimientos. Por los datos suministrados por las estratigrafías, parece que Sevilla y el Cerro Macareno surgieron un cuarto de siglo antes de la presencia Fenicia, según se desprende de la ausencia de materiales orientales en sus estratos inferiores. Este dato podría también explicarse por la introducción de las primeras cerámicas fenicias en un medio indígena del Bronce final y en un momento ligeramente posterior a los primeros contactos de exploración y pactos con los tartesios.

Lo que sí parece evidente es la rápida evolución y drásticos cambios sobrevenidos en la sociedad hispalense en lo que respecta a la demografía y a su aculturación. La innovación tecnológica se dejó sentir en la arquitectura, sustituida la cabaña de planta circular de barro y ramaje, como la del Carambolo alto, por la casa de planta rectangular, construida con zócalos de piedra y muros de adobe revocados de cal y almagre y con techumbre de vigas, posiblemente a doble vertiente, capaz de engendrar un nuevo tipo de urbanismo de viviendas adosadas, creando calles y espacios abiertos. Se adaptó un tipo de escritura, préstamo de la Fenicia (Correa 1992), el horno con bóveda de adobes de alta temperatura para la nueva industria cerámica torneada de tipología oriental y para la fusión de minerales de plata, cobre e hierro (Ruiz Mata y Fernández 1986). Cambió la indumentaria con la adaptación de la túnica oriental o el himation griego, sujeto mediante fíbulas de doble resorte y de otras tipologías de arco (Ruiz Delgado 1989) y ceñido por cinturones con broche metálico de tipo tartesio (Cerdeño 1981).

La alimentación del Bronce final, basada en los cereales, leguminosas y carne, se vio complementada con el uso de aceite, vino, gallina y huevos, alimentos introducidos por los fenicios.

En el terreno espiritual la aculturación afectó a los ritos funerarios, que paulatinamente pasaron de la inhumación tradicional a la incineración de los colonizadores, conservándose el túmulo de raíces indígenas sudportuguesas (Pellicer 1989). Políticamente, con la nueva economía de la comercialización de excedentes alimenticios y metalúrgicos, cambió la estructura social, surgiendo una clase de élite opulenta, capaz de adquirir ricos bienes exóticos de prestigio, constatados en los ajuares funerarios de las tumbas de Setefilla (Aubet 1982), Los Alcores (Bonsor 1899) o Huelva (Garrido 1970; Garrido y Orta 1978), consistentes en valiosos y artísticos objetos de marfil; huevos de avestruz, metalistería y orfebrería, cuyo más notable exponente sería el fabuloso tesoro del Carambolo, de marcado acento oriental (Kukhan y Blanco 1959).

Sevilla en el s. VII y VI a.C. se convirtió en un rico emporio comercial de carácter orientalizante, desarrollado en función del tráfico fluvial. Posiblemente su población era mixta e híbrida, de indígenas y orientales, convivían pacíficamente. La presencia de fenicios en la antigua Sevilla parece constatada por el topónimo Spal que en diversas lenguas semíticas significa "zona baja", "llanura verde" o "valle profundo" (Díaz Tejera 1982).

\section{VI.- LA ESTRATIGRAFÍA PROTOHISTÓRICA DE SEVILLA}

La dinámica evolutiva interna de Sevilla y la ampliación sucesiva de su primitivo emplazamiento han sido documentadas por cuatro cortes estratigráficos, realizados en las calles San Isidro, Fabiola, Argote de Molina y Cuesta del Rosario.

La excavación de San Isidoro (Campos y otros 1988) ofreció una estratigrafía de $9 \mathrm{~m}$ de potencia con 26 niveles, tres poblados prerromanos superpuestos y 6 fases culturales.

La primera fase (26-25) parece corresponder exclusivamente al Bronce final, tratándose de un hábitat, quizás temporal, de chozas como las antes descritas, no localizadas, con una supuesta cronología dentro de la segunda mitad del s. VIII a. C.. 
La segunda fase (niveles 24-20) es de carácter marcadamente orientalizante, con casas de planta rectangular de zócalos de piedra y muros de adobes revocados, fechadas desde fines del s. VIII al VI a.C. a través de sus cerámicas indígenas de retícula bruñida y por otras, fenicias de barniz rojo y pintadas polícromas y monócromas con motivos lineales y por la especie gris de occidente, destacándose cierta abundancia de ánforas fenicias y alguna copa jonia. Esta segunda fase halló su fin a causa de un devastador incendio, producido hacia el 500 a. C., cuyas causas quizás obedecieron a la intrusión cartaginesa, fenómeno que se registra igualmente en otros poblados del entorno.

La tercera fase (niveles 19-18) significa la transición del orientalizante fenicio al mundo turdetano o protoibérico, reedificándose las casas con la misma estructura anterior, en una fecha dictada por la cronología del Cerro Macareno, en la primera mitad del s. V a. C..

La cuarta fase (nivel 17) corresponde al ibérico o turdetano antiguo, con cerámicas a torno pintadas de tipología enmarcable en la segunda mitad del s. V a. C..

La quinta fase (niveles 16-13), según las ánforas púnicas presentes, debe fecharse en el s. IV, siendo un momento de gran auge comercial.

La sexta fase (niveles 12-10), del ibérico final, terminó con otro gran incendio, producido probablemente por Escipión a finales del s. III a. C., cuando fundó Itálica.

El corte estratigráfico practicado en el solar número 8 de la calle Fabiola por J. Escudero y J. Lorenzo en 1987, todavía inédito (Campos y otros 1988), alcanzó igualmente una potencia de $9 \mathrm{~m}$, con 34 niveles, de los cuales los 34-19 son prerromanos, distinguiéndose cuatro fases. La fase I (niveles 34-24) corresponde al orientalizante de los s. VII y VI a. C.. La fase II, ocupada por el nivel 23, es estéril, coincidiendo con el incendio y destrucción detectado al final de la fase II de San Isidoro hacia el 500 a.C.. La fase III está definida por los niveles 22-21, del ibérico antiguo, fechada en la primera mitad del s. V a.C. y paralela a la fase III de San Isidoro. La fase IV (niveles 20-19), también del ibérico, se corresponde con parte de la fase IV de San Isidoro.

Las excavaciones efectuadas en 1944 por F. Collantes de Terán en la Cuesta del Rosario, esquina calle Galindo, entregaron el primer documento estratigráfico de la Sevilla prerromana (Collantes de Terán 1977; Vera 1986). En principio, se distinguieron cuatro estratos prerromanos. El inferior, del ibérico pleno, fue fechado a mediados del s. IV a.C., descansando sobre un lecho de incendio. El estrato 2, del ibérico final, con una gran edificación, fue fechado en el s. III a.C.. El estrato 3 estaba sellado por otro incendio, producido a finales del s. III a.C., según un tesorillo de monedas cartaginesas, coincidiendo con el final de la fase VI de San Isidoro, donde se repetía el mismo fenómeno. Finalmente el estrato 4 es romano republicano, perfectamente documentado por la cerámica campaniense y por las ánforas.

Posiblemente a la excavación de la Cuesta del Rosario corresponden unos materiales sin contexto definido, existentes en el Museo Arqueológico de Sevilla, de claro carácter orientalizante, fechables en el s. VI a.C.

El cuarto documento de Sevilla de carácter estratigráfico prerromano proviene de las excavaciones efectuadas en 1983-84 en el solar no 7 de la calle Argote de Molina (Campos 1986), con una potencia de 8,60 m donde se distinguieron tres fases prerromanas. La fase I (niveles 34-30), del s. V a.C., con estructuras rectangulares, corresponde al ibérico antiguo. La fase II (niveles 29-26), caracterizada por un edificio destruido por un incendio, fue clasificado del ibérico pleno. La fase III (niveles 25-24), del ibérico final y fechado en el s. III a.C., terminó con una destrucción general provocada por incendio, paralelo a los de la fase VI de San Isidoro y del estrato 3 de la Cuesta del Rosario. 


\section{VII.- SÍNTESIS Y FASES DE LA EVOLUCIÓN DE LA CIUDAD PRERROMANA}

Con toda esta documentación resulta posible presentar un cuadro del nacimiento, de la dinámica cultural interna y de la expansión del primitivo núcleo urbano de la Sevilla prerromana, siendo plausible distinguir cuatro fases en la evolución del yacimiento, según la estratigrafía comparada.

La fase I, de fundación de la ciudad, se enmarca en un Bronce final de la segunda mitad del s. VIII a.C., momento en el que tendría lugar el primer contacto con los fenicios colonizadores, que, procedentes de la base nuclear gaditana, explorarían con sus vistosas naves el Bajo Guadalquivir. El poblado primitivo estaba emplazado en el sector NW de un islote delimitado, $500 \mathrm{~m}$ al W., por el Tagarete y, $250 \mathrm{~m}$ al E, por el brazo del Guadalquivir que, partiendo de la Puerta de Bibarragel, seguía por la Alameda de Hércules, Trajano, Campana, Tetuán-Sierpes y Plaza Nueva, para desembocar en el Arenal.

El núcleo de la población ocupaba los alrededores de la calle de San Isidoro y Luchana, con una supuesta extensión oval, en dirección N-S, de 3 Ha y una población de unos 200 habitantes, que morarían en un complejo de unas 40 chozas de planta circular, de barro y ramaje, de unos $4 / 5 \mathrm{~m}$ de diámetro, esporádicamente situadas y no localizadas, siendo su principal dieta proteínica el buey y el ciervo, según los análisis de fauna.

En el momento de su fundación, el establecimiento estaría integrado política y económicamente en la concentración del Carambolo, $3 \mathrm{~km}$ al W, la raíz nuclear de Sevilla, a expensas del cual nace ésta como un suburbio portuario y comercial para el intercambio de productos excedentes agropecuarios del entorno y metalíferos de plata y cobre, llegados por tierra desde Aznalcollar y Tejada y fluvialmente desde los bordes meridionales de Sierra Morena, a cambio de bienes de prestigio fenicios y de vino, aceite y perfumes.

La fase II es plenamente orientalizante, perdurando durante los s. VII y VI a.C. y sufriendo un devastador incendio hacia el 500 a.C., fenómeno que se detecta igualmente en otros yacimientos próximos, debido posiblemente a la actuación militar e imperialista de Cartago sobre el Sur peninsular después de la batalla de Alalia en el 535 a.C.

En esta fase, absorbida la población del cercano yacimiento de la Universidad Laboral, se observa una intensa actividad comercial y un momento de esplendor, según se constata por la calidad y cantidad de cerámicas fenicias de barniz rojo, grises de occidente, pintadas polícromas y monócromas y por las ánforas fenicias y griegas de Jonia. Se incrementa sustancialmente la ganadería bovina. La ciudad se expande con una arquitectura típicamente oriental, de espaciosas casas de planta rectangular de zócalos de piedra y muros de adobe encalados y pintados de almagre. En ella moraría una población híbrida de tartesios y fenicios. Puede suponerse que la superficie edificada alcanzaría, al menos, $4 \mathrm{Ha}$, lo que supone una población cercana al millar de habitantes en unas 150 ó 200 viviendas. La expansión de la ciudad se dirige hacia el NE, por las calles Galindo-Francos, y hacia el SE, por las calles Fabiola-Aire.

La fase III, del s. V-IV a.C., es testigo de la reconstrucción de la ciudad después del incéndio, cambiando la estructura social y desactivándose la integración política y económica del Carambolo, que no solo deja de ser centro de poder, sino que desaparece hacia el 480 a.C., absorbido por Sevilla, donde se concentra la población.

El s. V a.C. supone para Sevilla una crisis transitoria, reflejada en un registro arqueológico más pobre, con cerámicas típicamente ibéricas y ánforas de tipo púnico, ocasionada por una depresión económica, efecto de la interrupción del comercio fenicio con Oriente. La crisis da paso a un momento de rehabilitación del mundo ibero-púnico-turdetano con el cambio de la estructura social tartesia a otra más igualitaria. 
La ciudad prosigue su ampliación en dirección SW, hacia la calle Placentines-Mateos Gago, alcanzando una superficie de $10 / 12 \mathrm{Ha}$, cubiertas por unas 500 viviendas donde morarían unos 2.000 habitantes, cuyo sustento proteínico se basa ahora sustancialmente en la cabaña ovicaprina.

La fase IV, del s. III a.C., supone una notable recuperación económica, pese a las fuertes convulsiones ocasionadas en la segunda mitad de la centuria por las guerras y conflictos internos, que culminarán con la destrucción general de la ciudad, según las huellas de incendio, fechado al final del siglo por un tesorillo de monedas cartaginesas (Collantes de Terán 1977), incendio provocado probablemente por las legiones de Escipión hacia el 206 a.C., como consecuencia de la batalla de Ilipa.

A este momento corresponderían algunas tumbas de las necrópolis descubiertas extramuros en la zona del Prado de San Sebastián y de San Telmo (Fernández Chicarro 1968).

Las cuatro estratigrafías, base de este trabajo, naturalmente no son suficientes, presentando serias lagunas, que hemos intentado rellenar, con grandes reservas, con la apreciable ayuda arqueológica proporcionada por otros yacimientos del entorno sevillano.

\section{BIBLIOGRAFÍA}

ALMAGRO BASCH, M. (1966): Las estelas decoradas del Suroeste Peninsular. Bibl. Praeh. Hisp., VIII, Madrid.

y ARRIBAS, A. (1963): El poblado de la necrópolis megalítica de los Millares. Bibl. Praeh. Hisp. III. Madrid.

AMO, M.DEL (1975): "Enterramientos en cista de la provincia de Huelva". Huelva: Prehistoriay Antigüedad. Madrid, 109 y ss.

AMORES, F.(1982): Carta arqueológica de los Alcores (Sevilla). Sevilla.

AUBET, M. E. (1981): "Sepulturas de la edad del Bronce en la Mesa de Setefilla (Sevilla)". Madr. Mitt. 22: $127-149$.

- (1982): "Los enterramientos bajo túmulo de Setefilla". Huelva Arq. VI, 49-69.

BELÉN, M. y ESCACENA, J.L. (1995): "Interacción cultural: fenicios-indígenas en el Bajo Guadalquivir". Kolaios 4,69-101.

BERMÚDEZ, C. (1832): Sumario de las antigüedades romanas que hay en España. Madrid.

BINFORD, L. R. (1971): “Arqueología como Antropología”. C.A.S.E., 1, 3, 41-57.

BLANCE, B. (1971): Die Anfänge der Metallurgie auf der Iberischen Halbinsel. Stud. zu den Anfang der Metll. 4.

BLANCO, A. (1979): Historia de Sevilla. I, 1. La ciudad Antigua. Sevilla.

BONSOR, G. (1899): "Les colonies agricoles pré-romaines de la vallée du Betis". Revue Archéologique, 35. París.

BORJA, F. (1995): "Paleogeografía de las costas atlánticas de Andalucía durante el holoceno medio-superior". Tartessos, 25 años después. Jerez de la Frontera, 73-98.

BUERO M. S. y otros (1978): "Yacimiento del Bronce de Santa Eufemia". Arch. Hisp. LXI, 186, 59 y ss.

CAMPOS, J. (1986): Excavaciones arqueológicas en la ciudad de Sevilla. Elorigen prerromano y la ciudad romana. Sevilla.

CAMPOS, J. y otros (1988): Protohistoria de la ciudad de Sevilla. El corte estratigráfico de San Isidoro. 85-86. Sevilla.

CANDAU,F. (1.894): Prehistoria de la provincia de Sevilla. Sevilla.

CAÑAL, C. (1.894): Sevilla prehistórica. Yacimientos prehistóricos de la provincia de Sevilla. Madrid. 
CARO, R. (1932): Adiciones al principado y Antigüedades de la ciudad de Sevilla y su convento jurídico. Sevilla.

CARRIAZO, J. DE M. (1973): Tartesos y El Carambolo. Madrid.

- (1974): Protohistoria de Sevilla. Sevilla.

CERDEÑO, M L. (1981): "Los broches de cinturón tartesios". Huelva Arq. V, 31-56.

CHAPMAN, R. W. (1991): La formación de las sociedades complejas. El Sureste de la Península Ibérica en el marco del Mediterráneo Occidental. Barcelona.

CLARKE, D. L. (1984): Arqueología analítica. Barcelona.

COFFYN, A. (1985): Le Bronce Final Atlantique. Paris.

COLLANTES DE TERÁN, F. (1969): "El dolmen de Matarrubilla". V.Simp. Intern. Preh. Pen., Barcelona, 47-62.

- (1977): Contribución al estudio de la topografía sevillana en la antigüedad y la edad media. Sevilla.

CORREA, J. A. (1992): La epigrafía tartesia. Forum Ibero-Americanum 7. Andalusien. Köln, 75-114.

CRUZ-AUÑÓN, R. y JIMÉNEZ, J. C. (1986): "Historia crítica del antiguo yacimiento de Campo Real (Carmona)". Habis 16, 417-452.

DÍAZ DEL OLMO, F. (1989): "Paleogeografía tartésica". Tartessos. Sabadell, 13-23.

DÍAZ TEJERA, A. (1982): Sevilla en los textos clásicos greco-latinos. Sevilla.

DOMÍNGUEZ, M. C. y otros (1988): "Cerro de la Cabeza (Santiponce, Sevilla)". Not. Arq. Hisp. 30. Madrid. 121-186.

ESCACENA, J. L. (1983): "Problemas en torno a los orígenes del urbanismo a orillas del Guadalquivir". Gades, 11.

ESCACENA, J. L. y otros (1996): Guadalquivir salobre. Sevilla.

FERNÁNDEZ CHICARRO, C. (1968): Catálogo del museo arqueológico de Sevilla. Madrid.

FERNÁNDEZ GÓMEZ, F. y otros (1976): "Los enterramientos en cristal del cortijo de Chichina (Sanlúcar la Mayor, Sevilla)". Trab. Preh. 33, 351-380.

FERNÁNDEZ GÓMEZ, F. y RUIZ, D. (1978): "El Tholos del Cerro de la Cabeza en Valencina de la Concepción (Sevilla)". Trab. Preh. 35, 193-224.

FERNÁNDEZ GÓMEZ, F. y ALONSO, J. (1985): "Un fondo de cabaña campaniforme en la Universidad Laboral de Sevilla". Not. Arq. Hisp. 22, 7 y ss.

FERNÁNDEZ GÓMEZ, F. y OLIVA, D. (1986): "Valencina de la Concepción (Sevilla)". Rev. de Arqueología VII, 58, Madrid, 19-33.

GAMITO, T. J. (1988): Social complexity in Southwest Iberia. 800-300 B. C. The case of Tartessos. B.A.R., 439. Oxford.

GARRIDO, J. P. (1970): Excavaciones en la necrópolis de la Joya, Huelva. (E.A.E., 71). Madrid.

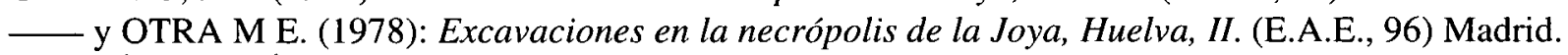

HERNÁNDEZ DÍAZ, J. y otros (1938): Catálogo arqueológico y artístico de la provincia de Sevilla. Sevilla.

HURTADO, V. y GARCÍA, L. (1994): “Áreas funcionales en el poblado de la Edad del Bronce de El Trastejón (Zufre, Huelva)". Arq. en el entorno del Bajo Guadiana. Huelva, 239-271.

ISIDORO, SAN: Originum sive Etymologiarum libri XX.

KUKHAN, E. y BLANCO, A. (1959): "El tesoro de El Carambolo". A. E. Arq. XXXII. 38-49.

MALUQUER, J. (1959): "El tesoro tartésico de El Carambolo". I Cong. Nac. Arq., Lisboa.

MENANTEAU, L. (1982): Les Marismas du Guadalquivir, exemple de transformation d'un paysage alluvial au cours du quaternarie récent. Paris.

PAÇO, A. DO y SANGMEISTER, E. (1953): "Vilanova de São Pedro. Eine befestigte Siedlung der Kupferzeit im Portugal". Germania 34.

PELLICER, M. (1989): "El Bronce reciente y los inicios del Hierro en Andalucía Occidental". Tartessos. Sabadell, 147-188. 
(1995): Tras la identidad de la arqueología. Málaga.

— y V. HURTADO (1987): "Excavaciones de la mesa de Gandul (Alcalá de Guadaira, Sevilla)". An. Arq. Andal. II (1986). Sevilla, 338-341.

- y otros (1982): El corte estratigráfico de la Casa de Venus (Itálica). (E.A.E. 121), Madrid, 11-28. y otros (1983): El Cerro Macareno. (E.A.E. 124), Madrid.

RENFREW, C. (1986): El alba de la civilización. La revolución del radiocarbono y la Europa prehistórica. Madrid.

RUIZ DELGADO, M. M. (1989): Fíbulas protohistóricas en el sur de la Península lbérica. Sevilla.

RUIZ GÁLVEZ, M. L. (1984): La Península Ibérica y sus relaciones con el círculo cultural atlántico. Univ. Complutense. Madrid.

RUIZ MATA, D. (1975): "Cerámicas del bronce del poblado de Valencina de la Concepción (Sevilla)". Madr. Mitt. 16,80-110.

(1983): "El yacimiento de la Edad del Bronce de Valencina de la Concepción (Sevilla) en el marco cultural del Bajo Guadalquivir". I Cong. Hist. Andalucía. Preh. y Arq., 183-208.

— y FERNÁNDEZ, J. (1986): "El poblado metalúrgico de época tartésica de San Bartolomé de Almonte (Huelva)". Huelva Arq. VIII.

SERNA, Ma R. y otros (1984): "Nuevos datos para la definición del Bronce antiguo y pleno en el Bajo Guadalquivir". B.A.R., 229. Oxford, 1052-1037.

SIRET, L. y H. (1890): “Las primeras edades del metal en el sureste español”. Barcelona.

VALLESPÍ, E. (1988): "Paleolítico medio de aspecto postachelense en la depresión inferior del Guadalquivir". Espacio, Tiempo y Forma, I, Preh. I, Madrid, 85-91.

VANNEY, J. R. (1970): L'Hydrologie du bas Guadalquivir. Madrid.

VERA, M. (1986): "Aportación al conocimiento de Sevilla Antigua”. Arch. Hisp. 


\begin{tabular}{|c|c|c|c|c|c|c|c|c|c|c|c|c|c|c|c|}
\hline $\begin{array}{l}\text { Horizonte } \\
\text { Cultural }\end{array}$ & $\begin{array}{c}\text { Cronología } \\
\text { A.C. }\end{array}$ & 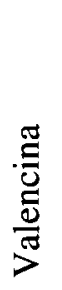 & 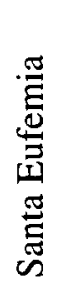 & 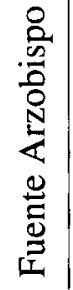 & 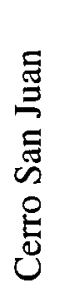 & 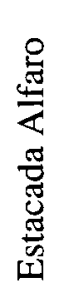 & 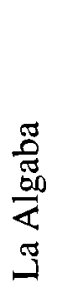 & 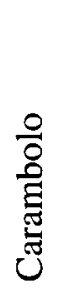 & 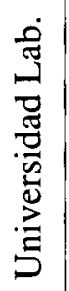 & 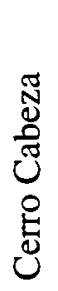 & 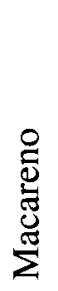 & $\begin{array}{l}\text { U. } \\
\text { : } \\
\text { : } \\
\text { : }\end{array}$ & 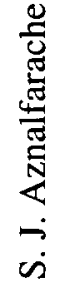 & 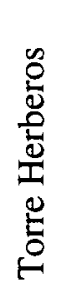 & $\begin{array}{l}\stackrel{3}{\overrightarrow{7}} \\
\stackrel{\vec{D}}{\tilde{n}}\end{array}$ \\
\hline Calcolítico & 3.000 & & & & & & & & & & & & & & \\
\hline Campaniforme & 2.200 & & 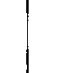 & & & & & & & & & & & & \\
\hline Bronce Pleno & 1.600 & ? & ? & & & $?$ & $?$ & $?$ & $?$ & & & & & & \\
\hline Bronce Final & 900 & & & & & & & & & & & & & & \\
\hline Orientalizante & 725 & & & & & & & & & & & & & & \\
\hline Turdetano & 500 & & & & & & & & & & & & & & \\
\hline Romano & 200 & & & & & & & & & & & & & & \\
\hline
\end{tabular}

Fig. 1.- Estratigrafía comparada, horizontes culturales y cronología de los yacimientos arqueológicos del entorno de Sevilla. 


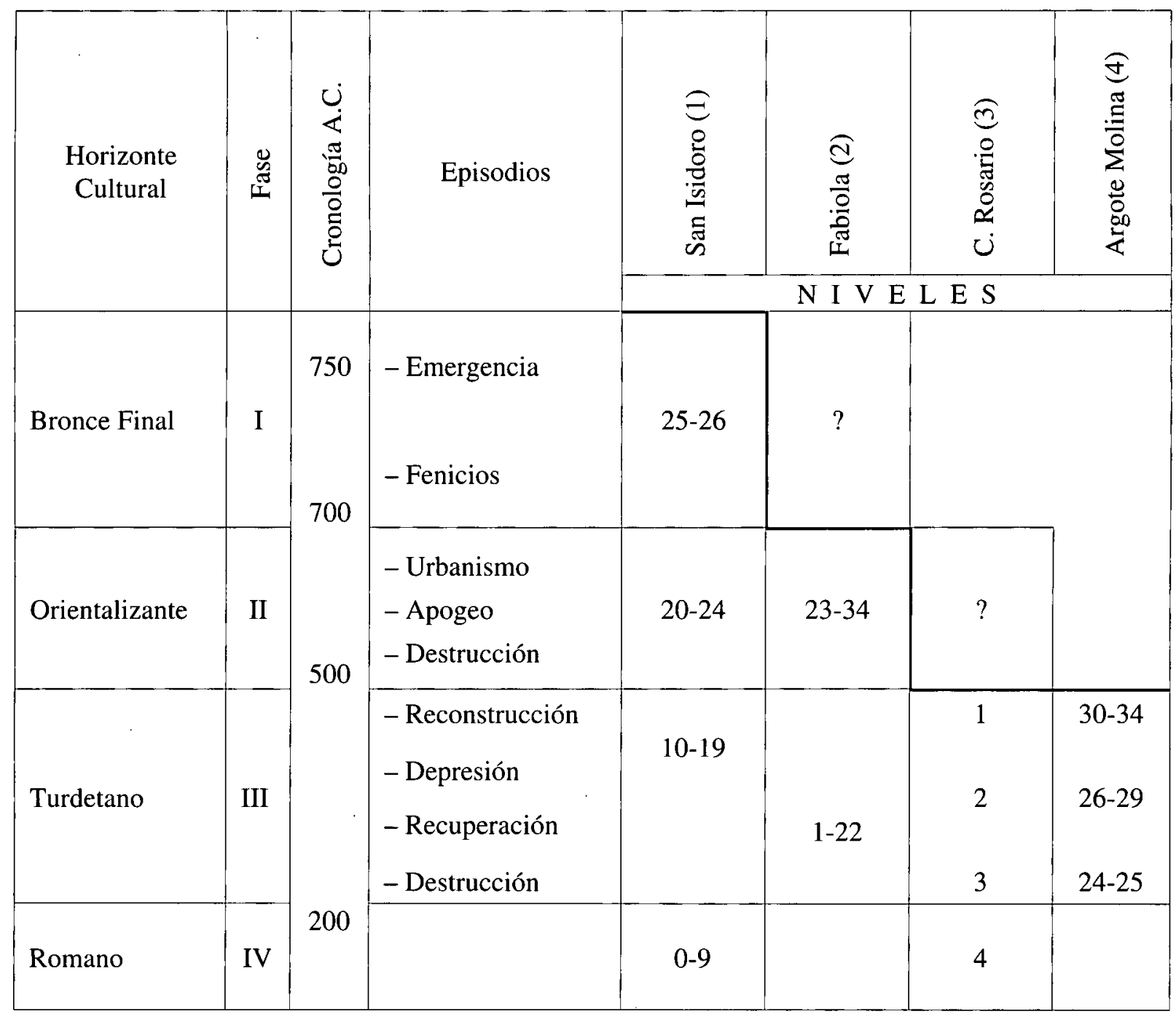

Fig. 2.- Estratigrafía comparada, horizontes culturales y cronología de los sondeos prerromanos de Sevilla. 